Research Paper

\title{
Re-analysis of SARS-CoV-2-infected host cell proteomics time-course data by impact pathway analysis and network analysis: a potential link with inflammatory response
}

\author{
Jens-Ole Bock ${ }^{1}$, Ignacio Ortea² \\ ${ }^{1}$ Cobo Technologies Aps, Maaloev 2760, Denmark \\ ${ }^{2}$ Proteomics Unit, Universidad de Cádiz and Instituto de Investigación e Innovación Biomédica de Cádiz (INiBICA), \\ Cádiz 11002, Spain
}

Correspondence to: Ignacio Ortea; email: nacho.ortea@inibica.es Keywords: COVID-19, SARS-CoV-2, inflammatory response, proteomics

Received: March 31, $2020 \quad$ Accepted: May 30, 2020

Published: June 23, 2020

Copyright: Bock et al. This is an open-access article distributed under the terms of the Creative Commons Attribution License (CC BY 3.0), which permits unrestricted use, distribution, and reproduction in any medium, provided the original author and source are credited.

\begin{abstract}
Coronavirus disease 2019 (COVID-19), caused by an outbreak of the severe acute respiratory syndromecoronavirus 2 (SARS-CoV-2) in Wuhan, China, has led to an unprecedented health and economic crisis worldwide. To develop treatments that can stop or lessen the symptoms and severity of SARS-CoV-2 infection, it is critical to understand how the virus behaves inside human cells, and so far studies in this area remain scarce. A recent study investigated translatome and proteome host cell changes induced in vitro by SARS-CoV2. Here, we use the publicly available proteomics data from this study to re-analyze the in vitro cellular consequences of SARS-CoV-2 infection by impact pathways analysis and network analysis. Notably, proteins linked to the inflammatory response, but also proteins related to chromosome segregation during mitosis, were found to be altered in response to viral infection. Upregulation of inflammatory response proteins is in line with the propagation of inflammatory reaction and lung injury that is observed in advanced stages of COVID-19 patients and which worsens with age.
\end{abstract}

\section{INTRODUCTION}

Coronavirus disease 2019 (COVID-19), caused by an outbreak of the severe acute respiratory syndromecoronavirus 2 (SARS-CoV-2) in Wuhan, China, has led to an unprecedented health and economic crisis worldwide [1]. Initially reported in December 2019 in the Chinese city of Wuhan, and potentially linked to a zoonosis related to a wild animal market, COVID-19 has rapidly spread globally, and the World Health Organization (WHO) declared a pandemic on March $11^{\text {th }} 2020$. As of May $25^{\text {th }}$ 2020, there are 5,304,772 confirmed cases and 342,029 confirmed deaths, with 216 countries affected (WHO, https://www.who.int, data accessed on May $25^{\text {th }} 2020$ ). These figures make COVID-19 the biggest health emergency of the $21^{\text {st }}$ century. With neither an effective treatment nor vaccine available, the main controlling measure taken by nations has been social distancing followed by partial or total preventative lockdown. These control measures alone have led to the biggest global economic crisis of the $21^{\text {st }}$ century.

COVID-19 typically manifests as an acute respiratory distress syndrome with fever, dry cough and breathing difficulties. Some patients, especially those with specific comorbidities, can rapidly deteriorate and die $[2,3]$. A large number of undocumented cases is expected, as a result of asymptomatic carriers and patients with mild symptoms who are not tested for SARS-CoV-2 [4, 5]. The crude global mortality rate is estimated to be $6.5 \%$ in WHO reports [6]. However, given the likely high number of undocumented cases it is difficult to calculate the true mortality rate globally and on a nation-wide basis. In any case, COVID-19 spreads at an alarming rate, and both mortality rate and severity increase with age and depend on pre-existing comorbidity, such as hypertension and diabetes, which are age-related diseases. This defines COVID-19 as an 
aging-dependent disease with outcomes determined by biological age.

To develop treatments that can stop or ameliorate the effects of SARS-CoV-2, we need to understand the biology of the virus and how it behaves inside human cells. This creates an urgent need to decipher the host cell molecular mechanisms that are triggered by viral infection. Cellular factors exploited by SARS-CoV-2 to gain entry into cells have recently been studied, revealing that the virus uses the angiotensin-converting enzyme 2 (ACE2) host cell receptor, together with the serine protease TMPRSS2. On this basis, a TMPRSS2 inhibitor has been proposed as a treatment option [7]. Elsewhere, it has been reported that ACE2 expression is protective against lung injury and that this is downregulated by SARS-CoV-1 [8, 9], which might promote lung injury, therefore worsening the prognosis of the disease, but it has not been demonstrated yet whether SARS-CoV-2 also interferes with ACE2 expression [7].

However, knowledge about what goes on inside human cells after the entrance of SARS-CoV-2 remains scarce.
Host cell proteomics studies that measure changes in protein abundance following viral entry and subsequent global pathway and network analysis can shed some light on the mechanisms that are used and/or altered by the virus and may reveal novel drug targets. To the best of our knowledge, the first available study describing translatome and proteome host cell changes induced by SARS-CoV-2 was conducted by Bojkova et al. [10]. Here, the authors used Cytoscape and ReactomeFI to propose overrepresented pathways that could be targeted by potential treatment compounds. In our study, we use the publicly available proteomics data from Bojkova et al. [10] to re-analyze the cellular mechanisms altered upon viral infection by impact pathways analysis [11] and network analysis.

\section{RESULTS}

The input dataset for the analysis, formatted from Bojkova et al. [10], is compiled in Supplementary Table 1. The implicated pathways were analyzed using iPathwayGuide software. Significantly impacted pathways according to our analysis are shown in Figure 1 (see Supplementary Tables 2, 3 for the results

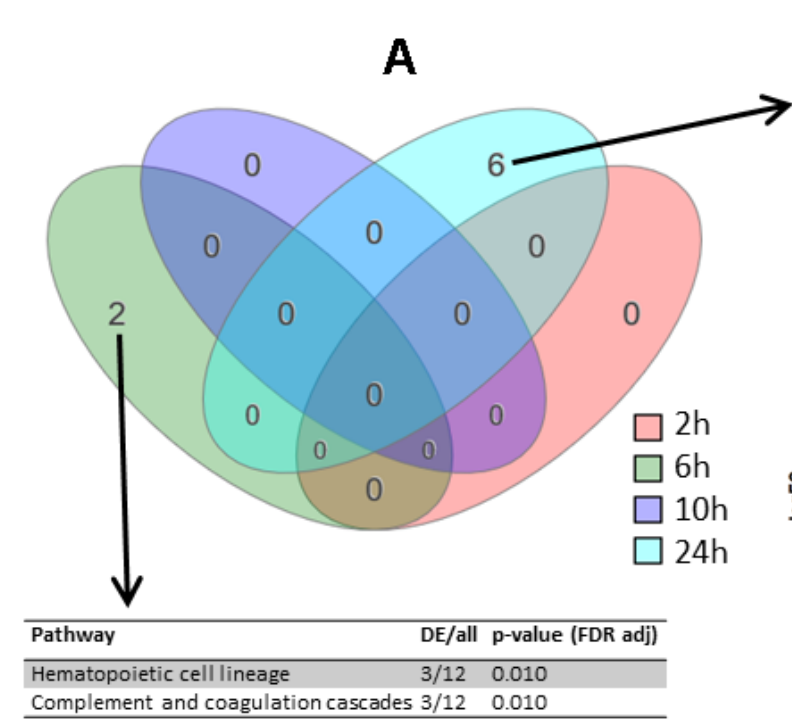

\begin{tabular}{lll}
\hline Pathway & DE/all & p-value (FDR adj) \\
\hline Transcriptional misregulation in cancer & $5 / 38$ & 0.043 \\
Proteoglycans in cancer & $6 / 96$ & 0.043 \\
Axon guidance & $3 / 64$ & 0.045 \\
Linoleic acid metabolism & $2 / 3$ & 0.045 \\
Neomycin, kanamycin and gentamicin biosynthesis $2 / 3$ & 0.045 \\
Neuroactive ligand-receptor interaction & $2 / 5$ & 0.045 \\
\hline
\end{tabular}

B
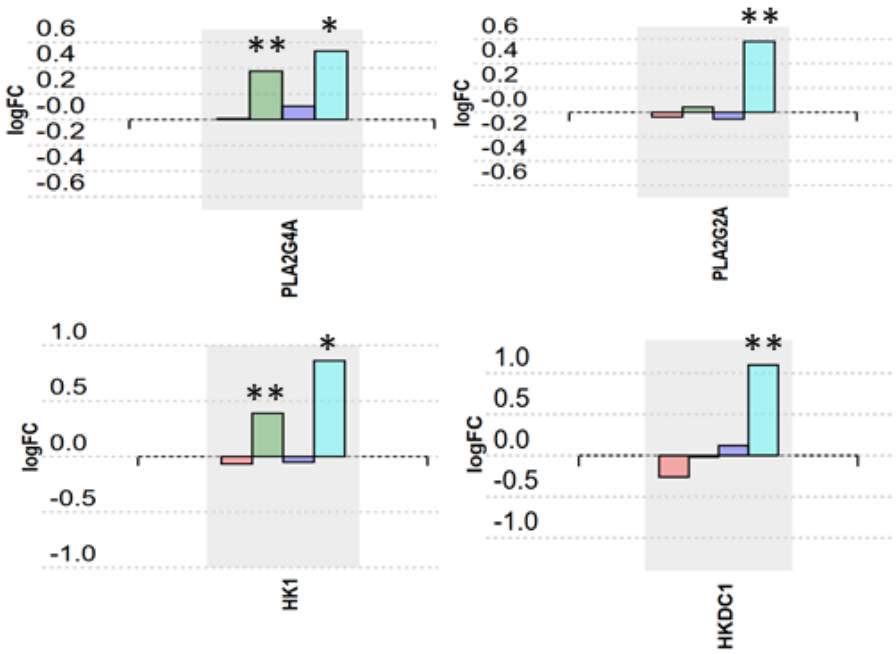

Figure 1. Pathway analysis results. (A) Venn diagram representing the intersections of pathway sets associated with the four postinfection time points. Pathways were considered significant according to a p-value calculated by iPathway Guide software using a hypergeometric distribution and adjusted using false discovery rate. DE, differentially expressed proteins. (B) Expression changes over four post-infection time points for proteins PLA2G4A, PLA2G2A, HK1, and HKDC1. * p-value $<0.05, * *$-value $<0.001$. 
from the pathway analysis for the metanalysis and for the $24 \mathrm{~h}$ time point, respectively). After false discovery rate (FDR) correction, six pathways were found to be significantly impacted at $24 \mathrm{~h}$ post-infection, two pathways were found to be significantly impacted at $6 \mathrm{~h}$ post-infection, and no pathways were found to be significantly impacted at $2 \mathrm{~h}$ and $10 \mathrm{~h}$ post-infection (Figure 1A). Expression changes for selected proteins over post-infection time points are shown in Figure 1B.

The differentially expressed proteins at the time point that revealed the most pronounced changes $(24 \mathrm{~h}$ postinfection), were subjected to network analysis using iPathwayGuide. The interactions included were activation, binding, catalysis, expression, and inhibition. Confidence score for protein-protein interaction was set at 900 (high). The resulting network is shown in Figure 2A. One of the subnetworks with the highest number of interactions, comprised of six proteins, is shown in Figure 2B, together with the expression change profile over post-infection time for these six proteins.

\section{DISCUSSION}

The significantly affected pathways were analyzed using iPathwayGuide software, which implements an 'impact analysis' approach, taking into consideration not only the over-representation of differentially expressed genes in a given pathway (i.e. enrichment analysis), but also topological information such as the direction and type of all signals in a pathway, and the position, role, and type of each protein [11]. Although

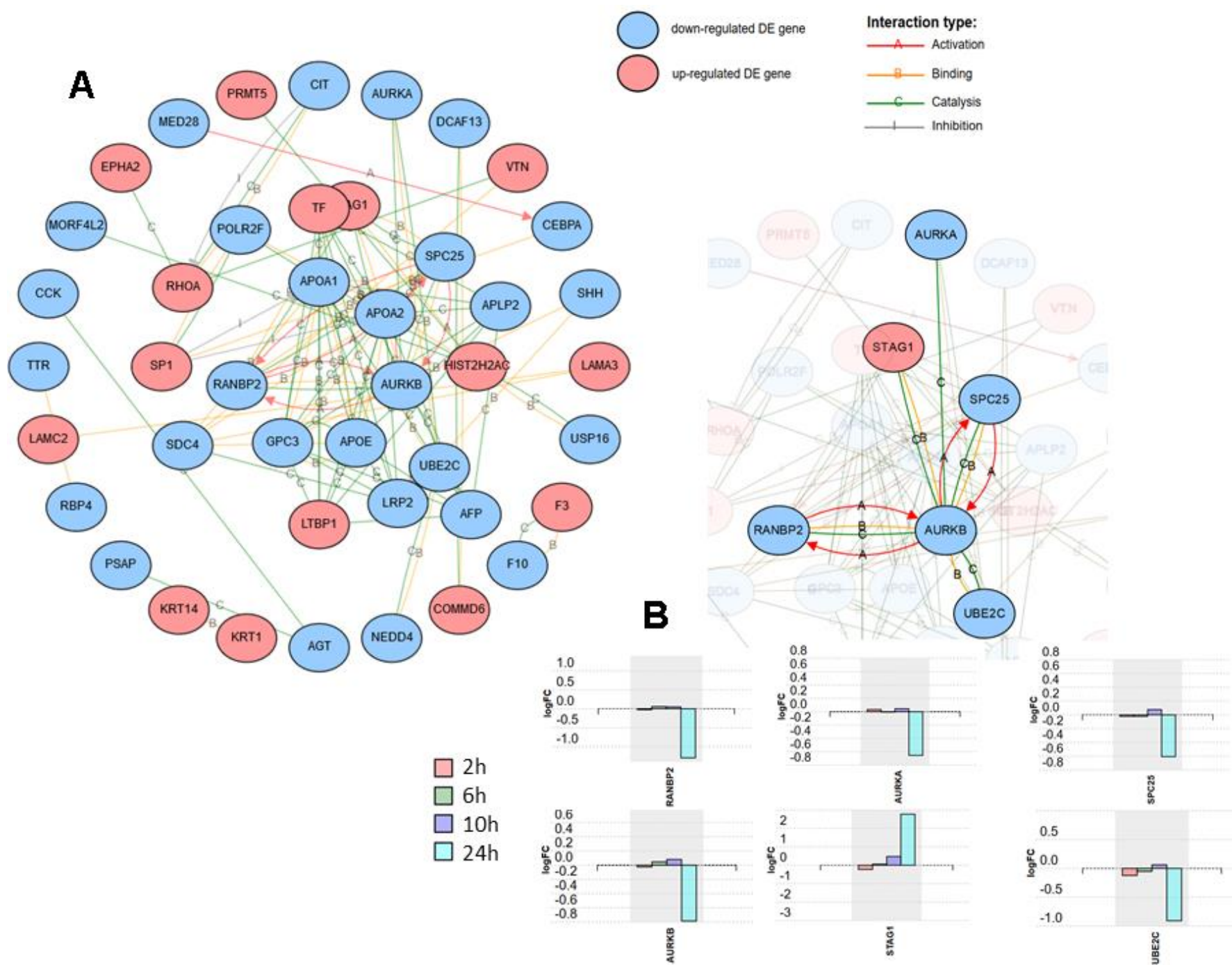

Figure 2. Network analysis including the 125 differentially expressed proteins at $\mathbf{2 4}$ h after SARS-CoV-2 in Caco-2 cells. Activation, binding, catalysis, and inhibition regulatory interactions are included. (A) Network with the isolated nodes hidden. (B) Six-protein subnetwork with the interactions for RANBP2, showing the expression changes for each time point for the six proteins. 
six pathways were found to be significantly impacted at $24 \mathrm{~h}$ post-infection, and two at $6 \mathrm{~h}$ post-infection, the number of differentially expressed (DE) proteins in these pathways was low (ranging from 2 to 6 proteins). For instance, the pathway 'transcriptional misregulation in cancer' had $5 \mathrm{DE}$ proteins out of the 38 proteins included in the pathway, the 'proteoglycans in cancer' pathway had $6 \mathrm{DE}$ proteins out of 96 in total in that pathway, and the 'axon guidance' pathway had $3 \mathrm{DE}$ proteins out of a total of 64 proteins in that pathway. Thus, we consider the experimental evidence for SARSCoV-2 having an impact on these mechanisms to be relatively weak. However, while the overall number of DE proteins was low, the ratio of DE proteins to total proteins in three other significant pathways was higher, and these warranted further attention. These three pathways are 'linoleic acid metabolism' pathway, 'neomycin, kanamycin and gentamicin biosynthesis' pathway, and 'neuroactive ligand-receptor interaction' pathway. The linoleic acid metabolism pathway is linked to arachidonic acid metabolism and eicosanoids pathway, and it could therefore play a role in the inflammatory response observed in disease stages II and III in COVID-19 patients [12]. In fact, the two proteins found to be differentially expressed in this pathway at 24 h post-infection, PLA2G4A (cytosolic phospholipase A2) and PLA2G2A (phospholipase A2, membrane associated), are key components of the phospholipase A2 group, which has previously been suggested to participate in a key mechanism of the inflammatory reaction [13]. Additionally, the contribution of the phospholipase A2 group to inflammation and eicosanoid profile in arthritis [14] and in cardiovascular diseases has been demonstrated [15]. When looking at the overall trend in protein expression over the whole time-course, PLA2G4A and PLA2G2A appear to share the same expression profile with a clear increase at $24 \mathrm{~h}$ post-infection (Figure 1B). This observation suggests that these two proteins may serve as early systemic biomarkers for COVID-19 infection.

Two proteins from the neomycin, kanamycin and gentamicin biosynthesis pathway were significantly upregulated at $24 \mathrm{~h}$ post-infection (Figure 1B). These are HK1 (hexokinase 1) and HKDC1 (hexokinase domain containing 1), which are proteins related to glucose use and homeostasis $[16,17]$. These proteins also belong to the glycolysis/gluconeogenesis pathway, since they participate in the first step of glycolysis where the glucose ring is phosphorylated. The 'glycolysis/ gluconeogenesis' pathway also appeared in our pathway analysis for the $24 \mathrm{~h}$ post-infection time point (although not statistically significant) (Supplementary Table 3), and, according to the nature of the cells used in the assay, it should be a better match than the aminoglycoside antibiotics biosynthesis pathway.
Interestingly, $\mathrm{HK}$ has previously been associated with the inflammatory response in autoimmune disorders, and deoxy-D-glucose (2-DG), an inhibitor of HK, has been proposed to ameliorate autoimmune inflammation [18]. Recently, 2-DG has been shown to inhibit SARSCoV-2 replication in Caco-2 cells [10], as well as inhibiting rhinovirus infection and inflammation in a murine model [19]. Given these findings, we believe that a potential link between hexokinase and SARS$\mathrm{CoV}-2$ infection and the related inflammation response deserves further investigation.

Figure 2A shows the network formed by the $\mathrm{DE}$ proteins, excluding isolated nodes. One of the subnetworks with a higher number of connections is the one formed by RANBP2 (E3 SUMO-protein ligase RanBP2) (Figure 2B). RANBP2 forms a complex at the nuclear pore with TRIM5 $\alpha$, a cytoplasmic restriction factor that blocks post-entry retroviral infection and is regulated by SUMO. It has been demonstrated that loss of RANBP2 blocked SUMOylation of TRIM5 $\alpha$, suppressing its anti-retroviral activity [20]. Here, RANBP2 exhibited a statistically significant foldchange $(\log )$ of -1.295 at $24 \mathrm{~h}$ post-infection, thus the role of RAMBP2-TRIM5 $\alpha$ in coronavirus infection deserves further consideration. In the same subnetwork as RANBP2, four other proteins that are interestingly related to cell cycle progression, AURKA, AURKB, SPC25 and STAG1, also deserve further attention (Figure 2B). They all participate in the regulation of chromosome segregation during mitosis [21-24]. Three of these four proteins were found to be down-regulated at $24 \mathrm{~h}$ post-infection except STAG1, which was strongly up-regulated. In this subnetwork, closely related to AURKB, and also down-regulated, is UBE2C (Ubiquitin-conjugating enzyme E2 C), which is an essential factor of the anaphase promoting complex/cyclosome (APC/C), a cell cycle-regulated ubiquitin ligase that controls progression through mitosis [25].

In parallel to re-analyzing the data with alternative tools, we also noticed a trend towards down-regulation of ACE2 over time post-infection (Figure 3). This had not been highlighted by the original authors [10]. In fact, at $24 \mathrm{~h}$ post-infection ACE2 presented a fold-change in expression $(\log )$ of $-0.168(\mathrm{p}$-value $=0.01)$. Coronavirus entry into target cells depends on binding of its spike (S) proteins to a cellular receptor, which facilitates viral attachment to the surface of target cells. ACE2 was reported as the entry receptor for SARS-CoV [26], another coronavirus closely related to SARS-CoV-2, therefore playing a key role in SARS-CoV transmissibility [27]. Similar findings were recently made for ACE2 and SARS-CoV-2 [7]. ACE2 is also a peptidase in the renin-angiotensin system, that converts 
angiotensin I to angiotensin (1-9) and angiotensin II to angiotensin (1-7), which is a vasodilator. ACE2's protective role in lung injury is therefore related to its ability to cleave angiotensin II [28, 29]. It was also reported that ACE2 expression protects from lung injury and is downregulated by SARS-CoV $[8,9]$, which might promote lung injury, therefore worsening the prognosis
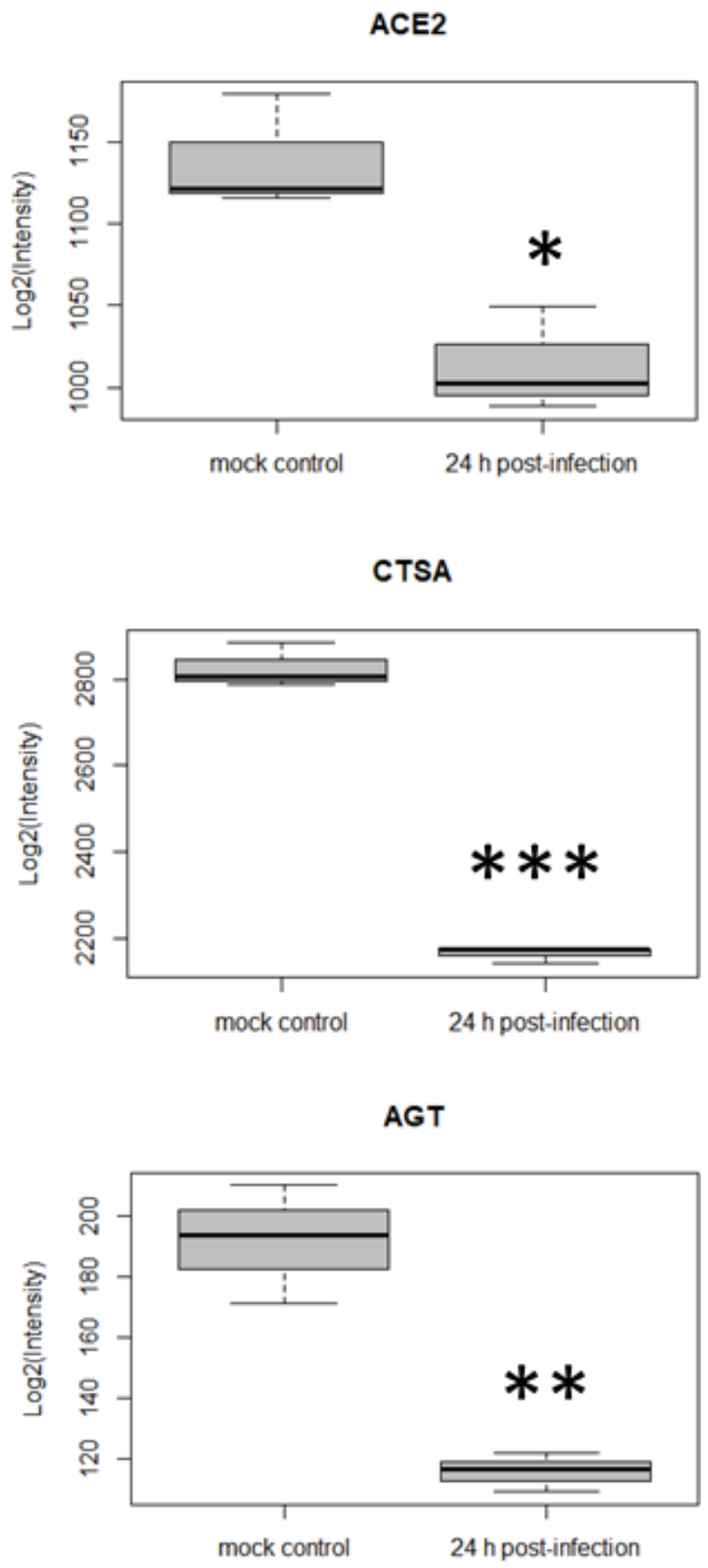

Figure 3. Differential expression for three host cell proteins in the renin-angiotensin system at $24 \mathrm{~h}$ post SARS-CoV-2 infection ( ${ }^{*}$ p-value $<0.05, \quad * *$ p-value $<0.01, \quad * * *$ p-value $<0.0001$, comparison to mock control). of the disease. Here, we highlight that SARS-CoV2 also seems to interfere with ACE2 expression, and this may be related to a higher level of lung injury as was demonstrated for SARS-CoV. When inspecting the quantitative data for other proteins in the reninangiotensin system, two other proteins were found to be down-regulated $24 \mathrm{~h}$ post-infection, namely cathepsin A (CTSA) and angiotensinogen (AGT) (Figure 3). We hypothesize that dysregulation of some of the key components of the renin-angiotensin system could be related to the lung injury and worsening observed in COVID-19.

It has also been suggested that differential levels of ACE2 in the cardiac and pulmonary tissues of younger versus older adults may be at least partially responsible for the worse outcomes seen in elderly COVID-19 patients [30]. Elderly people, especially those with hypertension and diabetes, have reduced ACE2 expression and increased levels of angiotensin II proinflammatory signaling. This cohort is therefore potentially more vulnerable to the ACE2 downregulation that is exasperated by SARS-CoV-2, and we hypothesize that this is one explanation for the exaggerated inflammation and worse outcomes observed in elder populations. The impact of reduced ACE2 expression, together with the poorer clinical outcomes observed when comorbidities are present [31], which is also generally associated to age, makes the link between COVID-19 and aging strong.

ACE inhibitors (ACE-Is) and angiotensin II receptor blockers (ARBs), two common therapies for hypertension, increase ACE2 levels in some tissues such as the myocardium, contributing to protection against cardiovascular disease (CVD) [32]. The observed downregulation of ACE2 by SARS-CoV-2 could suppress that increase in ACE2 levels mediated by ACE-Is and ARBs, thus counteracting their beneficial effects on hypertension and CVD [32], and explaining the poorer clinical outcome observed when these comorbidities are present. In any case, discontinuation of ACEIs/ARBs in hypertension patients with COVID-19 might further decrease ACE2 levels, therefore worsening disease prognosis. In support of this notion, a recent study found that COVID-19 patients with untreated hypertension presented higher mortality than those treated with ACE-Is/ARBs [33]. On the other hand, since ACE2 is the receptor for SARS-CoV-2 entry, some authors have speculated about a greater susceptibility to viral infection and disease severity upon the use of ACE-Is and ARBs [34]. However, as of today there is no scientific evidence pointing in that direction, and several scientific societies recommend that hypertension and CVD patients continue their treatments [32]. 
It is important to note that the use of a colon cell line could be seen as a potential limitation of the study. Superior airways and lungs are the primary targets for SARS-CoV-2, and therefore a primary airway epithelial cell type, such as human bronchial or tracheal epithelial cells (HBEpC/HTEpC) is likely to be a more appropriate model to predict the cell infection profile than the colon cell line used by Bojkova et al. [10]. However, although it was initially thought that SARS-CoV-2 could only infect airway cells, it has since been found to affect numerous tissues and organs, including the intestinal tract $[35,36]$. ACE2, the host cell receptor used by SARS-CoV-2 to enter cells, is distributed broadly across human tissues, with similar expression levels in the colon and lung [37, 38]. SARS-CoV-2 has also been found to replicate in gastrointestinal cells in vivo and it has been frequently detected in stool, with many patients developing gastrointestinal symptoms [39, 40]. These findings qualify colon cells as an appropriate model for studying SARS-CoV-2 infection and the primary human cell response. On the other hand, Caco-2 cells have been extensively used to study SARS-CoV and are highly permissible for SARS-CoV-2, allowing an analysis of a human model response to viral infection [10,41, 42].

In summary, this work, through a re-analysis of previous data on the protein expression changes caused by SARS-CoV-2 infection in a cellular model, we point out several proteins related to the inflammatory response and chromosomal segregation that might be modulated by SARS-CoV-2 infection. In the case of proteins related to inflammation, the up-regulation observed could be linked to the propagation of the inflammatory reaction and lung injury that is observed during advanced stages of COVID-19.

\section{MATERIALS AND METHODS}

\section{Publicly available proteomics data}

Proteome measurements from Bojkova et al. [10] were downloaded and used for subsequent analysis. This data consisted of the quantification of 6,381 proteins in human Caco-2 cell secretomes at four time points after infection with SARS-CoV-2 virus. According to Bojkova et al. [10], a TMT-labeling bottom-up quantitative proteomics approach was used to obtain the data, with high $\mathrm{pH}$ reverse phase peptide fractionation and mass spectrometry measurement of the peptides using a Thermo QExactive and a nano-liquid chromatography configuration.

\section{Impact pathway analysis and network analysis}

iPathwayGuide (Advaita Corporation, Plymouth, MI, USA) v1910, within the PIPPR pathways analysis framework (COBO Technologies Aps, Maaloev, Denmark), was used to identify significantly impacted pathways and for GO analysis. All quantified proteins were included in the analysis, and the threshold for considering a protein as differentially expressed (DE) was fold-change $(\log 2)$ higher than 0.5 and p-value below 0.05. Data was analyzed in the context of pathways obtained from the Kyoto Encyclopedia of Genes and Genomes (KEGG) database (Release 90.0+/05-29, May 2019). iPathwayGuide was also used for network analysis, using String v11.0 Jan 2019 and BioGRID v3.5.171 Mar 2019 as data sources. The interactions included were activation, binding, catalysis, expression, and inhibition. The confidence score for protein-protein interaction was set at 900 (high).

\section{Statistical analysis}

For impact pathway analysis, iPathwayGuide software calculated a p-value using a hypergeometric distribution. $\mathrm{P}$-values were adjusted using false discovery rate (FDR).

\section{CONFLICTS OF INTEREST}

The authors declare that there are no conflicts of interest.

\section{FUNDING}

Ignacio Ortea is funded by the Miguel Servet Programme (grant CP19/00164) from the Instituto de Salud Carlos III, which is co-funded by the European Social Fund.

\section{REFERENCES}

1. Wang C, Horby PW, Hayden FG, Gao GF. A novel coronavirus outbreak of global health concern. Lancet. 2020; 395:470-73. https://doi.org/10.1016/S0140-6736(20)30185-9 PMID:31986257

2. Chen N, Zhou M, Dong X, Qu J, Gong F, Han Y, Qiu Y, Wang J, Liu Y, Wei Y, Xia J, Yu T, Zhang X, Zhang L. Epidemiological and clinical characteristics of 99 cases of 2019 novel coronavirus pneumonia in Wuhan, China: a descriptive study. Lancet. 2020; 395:507-13. https://doi.org/10.1016/S0140-6736(20)30211-7 PMID:32007143

3. Wu Z, McGoogan JM. Characteristics of and important lessons from the coronavirus disease 2019 (COVID-19) outbreak in China: summary of a report of 72314 cases from the Chinese center for disease control and prevention. JAMA. 2020. [Epub ahead of print]. https://doi.org/10.1001/jama.2020.2648 PMID:32091533 
4. Li R, Pei S, Chen B, Song Y, Zhang T, Yang W, Shaman J. Substantial undocumented infection facilitates the rapid dissemination of novel coronavirus (SARS-CoV-2). Science. 2020; 368:489-93.

https://doi.org/10.1126/science.abb3221

PMID:32179701

5. Qiu J. Covert coronavirus infections could be seeding new outbreaks. Nature. 2020. [Epub ahead of print]. https://doi.org/10.1038/d41586-020-00822-x PMID:32203376

6. WHO. Coronavirus disease (COVID-19) Situation Report 125. 2020 May 24.

https://www.who.int/docs/defaultsource/coronaviruse/situation-reports/20200524covid-19-sitrep-125.pdf?sfvrsn=80e7d7f0 2

7. Hoffmann $M$, Kleine-Weber $H$, Schroeder $S$, Krüger $N$, Herrler T, Erichsen S, Schiergens TS, Herrler G, Wu NH, Nitsche A, Müller MA, Drosten C, Pöhlmann S. SARSCoV-2 cell entry depends on ACE2 and TMPRSS2 and is blocked by a clinically proven protease inhibitor. Cell. 2020; 181:271-80.e8.

https://doi.org/10.1016/j.cell.2020.02.052 PMID:32142651

8. Imai $Y$, Kuba K, Rao S, Huan Y, Guo F, Guan B, Yang P, Sarao $R$, Wada $T$, Leong-Poi $H$, Crackower MA, Fukamizu A, Hui CC, et al. Angiotensin-converting enzyme 2 protects from severe acute lung failure. Nature. 2005; 436:112-16.

https://doi.org/10.1038/nature03712

PMID:16001071

9. Kuba K, Imai Y, Rao S, Gao H, Guo F, Guan B, Huan Y, Yang P, Zhang Y, Deng W, Bao L, Zhang B, Liu G, et al. A crucial role of angiotensin converting enzyme 2 (ACE2) in SARS coronavirus-induced lung injury. Nat Med. 2005; 11:875-79.

https://doi.org/10.1038/nm1267 PMID:16007097

10. Bojkova D, Klann K, Koch B, Widera M, Krause D, Ciesek $S$, Cinatl J, Münch C. Proteomics of SARS-CoV-2infected host cells reveals therapy targets. Nature. 2020. [Epub ahead of print].

https://doi.org/10.1038/s41586-020-2332-7 PMID:32408336

11. Tarca AL, Draghici S, Khatri P, Hassan SS, Mittal P, Kim JS, Kim CJ, Kusanovic JP, Romero R. A novel signaling pathway impact analysis. Bioinformatics. 2009; 25:75-82.

https://doi.org/10.1093/bioinformatics/btn577 PMID:18990722

12. Siddiqi HK, Mehra MR. COVID-19 illness in native and immunosuppressed states: a clinical-therapeutic staging proposal. J Heart Lung Transplant. 2020; 39:405-07. https://doi.org/10.1016/j.healun.2020.03.012 PMID:32362390

13. Touqui L, Alaoui-El-Azher M. Mammalian secreted phospholipases A2 and their pathophysiological significance in inflammatory diseases. Curr Mol Med. 2001; 1:739-54.

https://doi.org/10.2174/1566524013363258 PMID:11899260

14. Duchez AC, Boudreau LH, Naika GS, Rousseau M, Cloutier N, Levesque T, Gelb MH, Boilard E. Respective contribution of cytosolic phospholipase $A 2 \alpha$ and secreted phospholipase a 2 IIA to inflammation and eicosanoid production in arthritis. Prostaglandins Other Lipid Mediat. 2019; 143:106340.

https://doi.org/10.1016/j.prostaglandins.2019.106340 PMID:31129176

15. Santoso A, Heriansyah T, Rohman MS. Phospholipase A2 is an inflammatory predictor in cardiovascular diseases: is there any spacious room to prove the causation? Curr Cardiol Rev. 2020; 16:3-10. https://doi.org/10.2174/1573403X15666190531111932 PMID: $\underline{31146670}$

16. Cárdenas ML, Cornish-Bowden A, Ureta T. Evolution and regulatory role of the hexokinases. Biochim Biophys Acta. 1998; 1401:242-64. https://doi.org/10.1016/s0167-4889(97)00150-x PMID: 9540816

17. Ludvik $A E$, Pusec $C M$, Priyadarshini $M$, Angueira $A R$, Guo C, Lo A, Hershenhouse KS, Yang GY, Ding X, Reddy TE, Lowe WL Jr, Layden BT. HKDC1 is a novel hexokinase involved in whole-body glucose use. Endocrinology. 2016; 157:3452-61. https://doi.org/10.1210/en.2016-1288 PMID:27459389

18. Stathopoulou C, Nikoleri D, Bertsias G. Immunometabolism: an overview and therapeutic prospects in autoimmune diseases. Immunotherapy. 2019; 11:813-29.

https://doi.org/10.2217/imt-2019-0002

PMID:31120393

19. Gualdoni GA, Mayer KA, Kapsch AM, Kreuzberg K, Puck A, Kienzl P, Oberndorfer F, Frühwirth K, Winkler S, Blaas D, Zlabinger GJ, Stöckl J. Rhinovirus induces an anabolic reprogramming in host cell metabolism essential for viral replication. Proc Natl Acad Sci USA. 2018; 115:E7158-65.

https://doi.org/10.1073/pnas.1800525115 PMID:29987044

20. Maarifi G, Fernandez J, Portilho DM, Boulay A, Dutrieux J, Oddos S, Butler-Browne G, Nisole S, Arhel NJ. RanBP2 regulates the anti-retroviral activity of $\operatorname{TRIM} 5 \alpha$ by SUMOylation at a predicted phosphorylated SUMOylation motif. Commun Biol. 2018; 1:193. 
https://doi.org/10.1038/s42003-018-0198-0 PMID:30456314

21. Carvalhal S, Ribeiro SA, Arocena M, Kasciukovic $T$, Temme A, Koehler K, Huebner A, Griffis ER. The nucleoporin ALADIN regulates aurora a localization to ensure robust mitotic spindle formation. Mol Biol Cell. 2015; 26:3424-38.

https://doi.org/10.1091/mbc.E15-02-0113 PMID:26246606

22. Yasui $Y$, Urano $T$, Kawajiri A, Nagata $K$, Tatsuka M, Saya $\mathrm{H}$, Furukawa K, Takahashi T, Izawa I, Inagaki M. Autophosphorylation of a newly identified site of aurora-B is indispensable for cytokinesis. J Biol Chem. 2004; 279:12997-3003.

https://doi.org/10.1074/jbc.M311128200 PMID:14722118

23. Bharadwaj R, Qi W, Yu H. Identification of two novel components of the human NDC80 kinetochore complex. J Biol Chem. 2004; 279:13076-85.

https://doi.org/10.1074/ibc.M310224200 PMID:14699129

24. Gregson HC, Schmiesing JA, Kim JS, Kobayashi T, Zhou $\mathrm{S}$, Yokomori K. A potential role for human cohesin in mitotic spindle aster assembly. J Biol Chem. 2001; 276:47575-82.

https://doi.org/10.1074/jbc.M103364200 PMID:11590136

25. Jin L, Williamson A, Banerjee S, Philipp I, Rape M. Mechanism of ubiquitin-chain formation by the human anaphase-promoting complex. Cell. 2008; 133:653-65.

https://doi.org/10.1016/i.cell.2008.04.012

PMID: 18485873

26. Li W, Moore MJ, Vasilieva N, Sui J, Wong SK, Berne MA, Somasundaran M, Sullivan JL, Luzuriaga K, Greenough TC, Choe H, Farzan M. Angiotensin-converting enzyme 2 is a functional receptor for the SARS coronavirus. Nature. 2003; 426:450-54.

https://doi.org/10.1038/nature02145 PMID:14647384

27. Li W, Zhang C, Sui J, Kuhn JH, Moore MJ, Luo S, Wong SK, Huang IC, Xu K, Vasilieva N, Murakami A, He Y, Marasco WA, et al. Receptor and viral determinants of SARS-coronavirus adaptation to human ACE2. EMBO J. 2005; 24:1634-43.

https://doi.org/10.1038/sj.emboj. 7600640 PMID:15791205

28. Jia H. Pulmonary angiotensin-converting enzyme 2 (ACE2) and inflammatory lung disease. Shock. 2016; 46:239-48.

https://doi.org/10.1097/SHK.0000000000000633 PMID:27082314

29. Nicholls J, Peiris M. Good ACE, bad ACE do battle in lung injury, SARS. Nat Med. 2005; 11:821-22. https://doi.org/10.1038/nm0805-821

PMID:16079870

30. AlGhatrif M, Cingolani O, Lakatta EG. The dilemma of coronavirus disease 2019, aging, and cardiovascular disease: insights from cardiovascular aging science. JAMA Cardiol. 2020. [Epub ahead of print]. https://doi.org/10.1001/jamacardio.2020.1329 PMID: $\underline{32242886}$

31. Guan WJ, Liang WH, Zhao Y, Liang HR, Chen ZS, Li YM, Liu XQ, Chen RC, Tang CL, Wang T, Ou CQ, Li L, Chen PY, et al, and China Medical Treatment Expert Group for COVID-19. Comorbidity and its impact on 1590 patients with COVID-19 in China: a nationwide analysis. Eur Respir J. 2020; 55:2000547. https://doi.org/10.1183/13993003.00547-2020 PMID:32217650

32. Sarzani R, Giulietti F, Pentima CD, Giordano P, Spannella $F$. Severe acute respiratory syndrome coronavirus 2 infection, angiotensin-converting enzyme 2 and treatment with angiotensin-converting enzyme inhibitors or angiotensin II type 1 receptor blockers. Eur J Prev Cardiol. 2020. [Epub ahead of print]. https://doi.org/10.1177/2047487320918421 PMID: $\underline{32290680}$

33. Zhang $P$, Zhu L, Cai J, Lei $F$, Qin JJ, Xie J, Liu YM, Zhao $Y C$, Huang $X$, Lin L, Xia $M$, Chen MM, Cheng $X$, et al. Association of Inpatient Use of AngiotensinConverting Enzyme Inhibitors and Angiotensin II Receptor Blockers With Mortality Among Patients With Hypertension Hospitalized With COVID-19. Circ Res. 2020; 126:1671-1681.

https://doi.org/10.1161/CIRCRESAHA.120.317134 PMID:32302265

34. Diaz JH. Hypothesis: angiotensin-converting enzyme inhibitors and angiotensin receptor blockers may increase the risk of severe COVID-19. J Travel Med. 2020; 27:taaa041. https://doi.org/10.1093/jtm/taaa041 PMID:32186711

35. Vetter $P, V u$ DL, L'Huillier AG, Schibler M, Kaiser L, Jacquerioz F. Clinical features of covid-19. BMJ. 2020; 369:m1470.

https://doi.org/10.1136/bmi.m1470 PMID: $\underline{2303495}$

36. Zhou J, Li C, Liu X, Chiu MC, Zhao X, Wang D, Wei Y, Lee A, Zhang AJ, Chu H, Cai JP, Yip CC, Chan IH, et al. Infection of bat and human intestinal organoids by SARS-CoV-2. Nat Med. 2020. [Epub ahead of print]. https://doi.org/10.1038/s41591-020-0912-6 PMID:32405028

37. Bertram S, Heurich A, Lavender H, Gierer S, Danisch S, Perin P, Lucas JM, Nelson PS, Pöhlmann S, Soilleux EJ. 
Influenza and SARS-coronavirus activating proteases TMPRSS2 and HAT are expressed at multiple sites in human respiratory and gastrointestinal tracts. PLoS One. 2012; 7:e35876.

https://doi.org/10.1371/journal.pone.0035876

PMID:22558251

38. Li MY, Li L, Zhang Y, Wang XS. Expression of the SARSCoV-2 cell receptor gene ACE2 in a wide variety of human tissues. Infect Dis Poverty. 2020; 9:45. https://doi.org/10.1186/s40249-020-00662-x PMID:32345362

39. Xiao F, Tang M, Zheng X, Liu Y, Li X, Shan H. Evidence for gastrointestinal infection of SARS-CoV-2. Gastroenterology. 2020; 158:1831-3.e3. https://doi.org/10.1053/j.gastro.2020.02.055 PMID:32142773

40. Young BE, Ong SW, Kalimuddin S, Low JG, Tan SY, Loh J, Ng OT, Marimuthu K, Ang LW, Mak TM, Lau SK,
Anderson DE, Chan KS, et al, and Singapore 2019 Novel Coronavirus Outbreak Research Team. Epidemiologic features and clinical course of patients infected with SARS-CoV-2 in Singapore. JAMA. 2020; 323:1488-94. https://doi.org/10.1001/jama.2020.3204 PMID:32125362

41. Cinatl J, Morgenstern B, Bauer G, Chandra P, Rabenau $\mathrm{H}$, Doerr HW. Treatment of SARS with human interferons. Lancet. 2003; 362:293-94. https://doi.org/10.1016/s0140-6736(03)13973-6 PMID:12892961

42. Hoehl S, Rabenau H, Berger A, Kortenbusch M, Cinatl J, Bojkova D, Behrens P, Böddinghaus B, Götsch U, Naujoks F, Neumann $P$, Schork J, Tiarks-Jungk $P$, et al. Evidence of SARS-CoV-2 infection in returning travelers from wuhan, China. N Engl J Med. 2020; 382:1278-80. https://doi.org/10.1056/NEJMc2001899 PMID:32069388 


\section{SUPPLEMENTARY MATERIALS}

\section{Supplementary Tables}

Please browse Full Text version to see the data of Supplementary Tables 1 to 3.

Supplementary Table 1. Input dataset formatted from Bojkova et al. [10]. P-values and fold-changes are included for each of the quantified proteins at four different time points following SARS-CoV-2 infection of Caco-2 cells.

Supplementary Table 2. Pathway analysis meta-analysis results for the four time points investigated. Proteins were considered as differentially expressed (DE) when statistical analysis led to a $p$-value $<0.05$ and a fold change(log) $>0.5$ or $<-0.5$.

Supplementary Table 3. Expanded pathway analysis result for the $24 \mathrm{~h}$ time point. Proteins were considered as differentially expressed (DE) when statistical analysis led to a $p$-value $<0.05$ and a fold change(log) $>0.5$ or $<-0.5$. 